\title{
Organisational Transformation as a Consequence of Software-as-a-Service Usage by Small and Medium Enterprises
}

\author{
Khalid Alshammari \\ School of Business Information Technology and Logistics \\ RMIT University \\ Melbourne, Australia \\ Email: khha.alshammari@rmit.edu.au
}

\section{Arthur Adamopoulos}

School of Business Information Technology and Logistics

RMIT University

Melbourne, Australia

Email: arthur.adamopoulos@rmit.edu.au

\section{Martin Dick}

School of Business Information Technology and Logistics

RMIT University

Melbourne, Australia

Email: martin.dick@rmit.edu.au

\begin{abstract}
Cloud computing, and particularly Software-as-a-Service, is now in widespread use, but how organisations are potentially transformed by Software-as-a-Service usage needs greater understanding. How do organisations, particularly Small and Medium Enterprises, change their processes and structures after a period of time of using Software-as-a-Service solutions? This study used a qualitative method of investigation. Sixteen semi-structured interviews have been conducted with participants from eleven different organisations. It was found that all the organisations experienced transformation to some extent. The types of organisational transformation observed included changes to organisational processes, changes to the structures within the organisations and also changes to the role played by IT departments. Relationships between these forms of transformation were also found. A greater understanding of these transformations can help organisations gain greater benefits from Software-asa-Service solutions.
\end{abstract}

Keywords Software-as-a-Service, Organisational Transformation, Cloud Computing, SMEs, SaaS Consequences 


\section{Introduction}

While there have been considerable studies into cloud computing adoption, relatively few studies have looked beyond the adoption phase to how longer-term usage of cloud computing, and Software-as-aService (SaaS) in particular, changes and impacts an organisations' business processes. Organisations can face challenges in fitting their processes to the SaaS solution. Does the software change to fit the organisation or does the organisation change to fit the software? Consequences are the changes and impacts that occur within organisations after adopting a cloud solution for a certain amount of time. Consequences could be both positive and negative.

While it will impact all firms, cloud computing is especially relevant to small and medium enterprises (SME). SMEs are more responsive to rapid changes in technologies and usually have simpler IT requirements and need less support compared to large enterprises. Also, many of them are happy to pass the IT operations on to third party providers, which make them more flexible and give them the ability to focus on their core business (Bose and Sugumaran 2008; Taylor et al. 2010; Vijeikis and Makstutis 2009). This study chose to focus on SMEs for these reasons.

Cloud computing is often classified into three service models: Software-As-A-Service (SaaS), PlatformAs-A-Service (PaaS) and Infrastructure-As-A-Service (IaaS) (Liu et al. 2011). SaaS provides the end-user customer access to the providers' software applications, which can be accessed through client devices and interfaces such as web browsers (Low et al. 2011). SMEs are most likely to adopt SaaS cloud solutions over the other service models. Therefore, this study chose to focus on the consequences of SaaS usage by SMEs.

The main motivation of this paper is to present a clearer understanding of the organisational transformations that occur within SMEs after they have used SaaS solutions for a period of time. It presents three main categories of transformations and their conceptual relationships. These findings can assist organisations to anticipate, plan for and gain greater benefits from Software-as-a-Service solutions.

\section{Background}

Cloud computing has become a major solution that is now in wide use in the world. Gartner (2017) claims that by 2020 the projected revenues of cloud computing will exceed $\$ 38 \mathrm{oB}$ compared to $\$ 246 \mathrm{~B}$ in 2017. This innovation enables information to be stored, implemented, and retrieved online as a service to the customers in a pay-per-use manner (Taylor et al. 2010).

\subsection{Consequences of Software-as-a-Service usage}

Although most of the literature in SaaS adoption emphasises technologies and business models (Arya et al. 2010; Concha et al. 2010; Hudli et al. 2009), it does provide valuable elements such as technology understanding and business models which can lead to SaaS adoption understanding (Van Belle 2012). SaaS has been presented as a solution for small and medium enterprises (Dubey and Wagle 2007; Kern et al. 2002). Organisations do, however, have to weigh the benefits of SaaS (reliability, ease of deployment, scalability and security) with the drawbacks and risks associated with SaaS services (trust, availability, ownership, privacy and vendor lock-in) (Erdogmus 2009). The longer-term consequences of SaaS usage, however, have not been explored in depth.

\subsection{Enterprise Systems}

Studies into Enterprise Systems (ES) may provide insights into the potential consequences of SaaS usage. Small and medium enterprises can benefit from Enterprise Systems (ES) such as ERP systems as they serve as business tools to enhance enterprise growth. However, there is a need to distinguish between financial and non-financial benefits, which may occur when adopting ES in organisations (Reuther and Chattopadhyay 2004). Return on investment, cost reduction or other impacts that affect the spending positively can be considered as financial benefits. Whereas, efficiency and organisational effectiveness along with improvement in decision making process can be considered as non-financial benefits. Enterprise Systems generally make SMEs more responsive to market changes (Gupta 2000).

Enterprise Systems increase the enterprise's value and can make huge improvements to the enterprise business processes (Shaio Yan et al. 2009). Therefore, Enterprise Systems empower modern businesses with digital tools and information, which makes it hard to compete if they are not equipped with such systems. Also, an ES can integrate with the business' processes which make the exchange of information and data across the organisation more effective and in real time. Thus, efficiency and effectiveness are 
associated with ES which helps organisations to be more flexible and competitive. ES also promote flatter organisational structures and decentralised decision making (Beheshti and Beheshti 2010; Madapusi and D'Souza 2012; Stuart et al. 2010).

Previously, SMEs were not able to obtain such ES to support their operations easily due to their cost. With Enterprise Systems now available as Software-as-a-Service solutions, small and medium enterprises can now compete with larger organisations. SaaS helps SMEs to focus more on their core business and lower the cost of ownership. Moreover, it gives SMEs the ability to get access to cuttingedge technologies with no upgrade obligation. It enhances the overall business process and enables organisations to carry out data transactions along the value chain (Low et al. 2011).

\section{Organisational Transformation}

Organisations that move to cloud computing services such as Software-as-a-Service should expect some changes (Srinivasan 2013). Previous studies have primarily focussed on changes to the role of the IT department and personnel as well as how organisations change their structures and business models.

\subsection{Changing Role of the IT Department}

The roles and responsibilities of the IT department in an organisation will certainly be changed after adopting SaaS (Culley and Panteli 2015). These changes will impact every aspect of IT department operations. After SaaS adoption, many of the IT department's roles are shifted and transferred to the Cloud Service Provider (CSP). This is especially the case where previously, IT departments were full of employees who code, build, monitor and maintain systems. Culley and Panteli (2015 argue that IT departments should focus on information related to business rather than focusing on technology itself and maintaining it. Also, IT departments may take on new roles such as: governance, strategic business link, Design IT solution and delivery of the service.

Yanosky (2008 argues that cloud solution adoption will challenge the authority of the IT department. IT departments will lose power and influence over the user and other departments. Yanosky states that cloud adoption empowers the end user, "turning users into choosers". He encourages IT departments to redefine their roles and responsibilities in order to adapt to the change. They have to reassess their previous role of providing full support to a role of providing better control and monitoring of cloud services.

SaaS solutions can also impact the role of IT personnel directly. SaaS solution adoption transfers the burden of maintaining and supporting the organisation's systems and infrastructures to the CSP. So, SaaS solution can have a major positive impact as it offloads maintenance and other daily responsibilities to the SaaS providers which leads to a change in overall IT responsibilities (Azarnik et al. 2013; Berman et al. 2012). Offloading technical burdens helps the IT personnel to focus and pay more attention to supporting business functions efficiently (Al-lawati and Al-Badi 2016; Avram 2014). Therefore, SaaS solution adoption enables the IT department to change and to become more effective and efficient. Thus, it helps them to provide plans and strategies to the business in terms of technological solutions that serve the business needs (McKendrick 2011).

With the advent of SaaS, the abilities and skills of IT personnel could also be tested. IT department personnel need to improve their skills to keep up with the new advancements (Lin and Chen 2012). They need to update their knowledge in areas related to the cloud and understand cloud architecture, development, implementation and operation (Oredo and Njihia 2014).

Moving to cloud and SaaS services can also have major impacts on the role of IT management. McKendrick (2011) states that SaaS solution adoption "in many cases, it is elevating the role of IT-savvy managers within many enterprises". Delivering efficient and flexible IT systems is one of the Chief Information Officer's (CIO) major concerns to help the organisation to be more agile. With the SaaS solution capability to deliver flexible systems, the CIO can move their attention to the strategic level rather than operational level (Malladi and Krishnan 2012). Fisher (2014 argues that CIO role will receive huge and significant shift due to moving to the cloud, transforming the role from "Chief Information Officer" to "Chief Innovation Officer".

Lacity and Reynolds (2014 interviewed key personnel in four different SMEs that adopted cloud computing. They reported that the cloud adoption allowed in-house IT personnel to focus more on improving business processes. The change in duties and being free from technical support make them more strategic. One of the organisations, however, did not report major changes IT personnel duties. They swapped from an IT contractor to a cloud service provider. 


\subsection{Organisational Changes}

Adopting Software-as-a-Service solutions allows organisations to have access to the latest and cuttingedge technology and Enterprises Systems such as ERP, CRM and HRM (Rajendran 2013). Adopting all these ES software or one of them will make a huge impact on an organisation's operations and processes (Shaio Yan et al. 2009; Stuart et al. 2010; Zhao et al. 2014). According to (Rajendran 2013) the change in business operation models may lead to a change in organisational culture and structure.

Hugos and Hulitzky (2010 argue that the business will shift from control over its' resources to a collaboration stage which will be more profitable as the business will work closely with partners and suppliers. A study conducted by Ahokangas et al. (2014 on two organisations which moved to the cloud found that changes to the business model was the biggest challenge, requiring changes to the existing business model, impacting the value proposition, delivery of service and basis of pricing (Ahokangas et al. 2014).

Organisational changes can come in many forms and may be positive or negative. It can partly depend upon how much existing business processes are aligned with the standardised business processes of the SaaS solution (Khajeh-Hosseini et al. 2010). Also, the changes can be influenced by organisation size and industry. According to Mabert et al. (2003, SMEs are more likely to be able to change and transform their business processes to adapt to the new system. In contrast, larger companies are more likely to customise the system to fit their needs. SMEs also tend to implement the entire new system whereas larger companies are more likely to follow an incremental approach (Mabert et al. 2003).

According to Saul et al. (2012, adopting cloud based ES solution can help to improve the organisation's value chain, by improving the organisation's ability to collaborate with partners and increase operational efficiency (Saul et al. 2012). Cloud ES solutions can also help with operational transparency, giving managers a clearer view of the organisation's performance. This allows managers to identify business processes that need to be improved (Hendricks et al. 2007; Lewandowski et al. 2013).

\section{Methodology}

The methodology chosen to conduct this study was a qualitative case study. Grounded Theory was used to understand and describe the real experiences of real organisations adopting Software-as-a-Service. In order to improve and increase the research's validity, a research plan for the case study was developed based on the research process described by Eisenhardt (1989). The research plan includes the following steps:

- Getting Started: Defining the research questions.

- Selecting Cases: Eleven Small and Medium Enterprises.

- Crafting Instruments and protocols: Development of the interview instruments.

- Entering the field: Conducting sixteen interviews with SaaS adopters.

- Data Analysis: Applying Grounded Theory data analysis techniques using Atlas.ti software.

- Shaping hypotheses: Multiple iterations of data analysis develop the concepts in the theory

- Building Theory: Hypotheses evolves into a cohesive theory

Case studies that were recruited for this study were small or medium enterprises in Saudi Arabia. In order to ensure adoption had already occurred, companies had to have implemented SaaS for at least six months. Permission was obtained to interview one or more decision-makers in each organisation. These included the owners/executives who made the final decision, and other employees. Those interviewed were involved either in the early stage of decision-making such as IT directors and managers, or they were current users of the solution.

Sixteen people who met the recruiting criteria were interviewed from eleven different organisations in late 2016. A diversity of organisational backgrounds allowed the researcher to explore the situation of SaaS adoption and consequences from different perspectives. Table 1 gives a detailed profile of the case studies recruited for this study.

All interviews were fully transcribed. Analysis was then performed using the Atlas.ti qualitative data analysis software. Grounded Theory as described by Strauss and Corbin (1998) was selected as the methodology for this study. The interviews were coded using open and axial coding.

These codes were then refined and categorised into three main categories of transformation. These categories were further explored by investigating the conceptual relationships between them. The next 
Australasian Conference on Information Systems

Alshammari et al. 2018, Sydney

Organisational Transformation as a Consequences of SaaS Usage

section presents these transformational categories and relationships, with supporting quotations from the data.

\begin{tabular}{|c|c|c|c|c|c|c|c|}
\hline$\#$ & $\begin{array}{c}\text { Firm } \\
\text { Size }\end{array}$ & Industry & SaaS Type & $\begin{array}{l}\text { Number of } \\
\text { Participants }\end{array}$ & Position & $\begin{array}{l}\text { Years in } \\
\text { Company }\end{array}$ & $\begin{array}{c}\text { Degree of } \\
\text { Involvement }\end{array}$ \\
\hline 1 & Medium & $\begin{array}{c}\text { Retail \& } \\
\text { Distribution }\end{array}$ & ERP & 1 & $\begin{array}{c}\text { IT } \\
\text { Director }\end{array}$ & 6 & High \\
\hline 2 & Medium & Pharmaceutical & ERP & 1 & IT Mgr & 10 & High \\
\hline 3 & Small & Training & $\begin{array}{c}\text { Databases } \\
\text { / Web } \\
\text { Service }\end{array}$ & 1 & CEO & 5 & High \\
\hline 4 & Small & Internet Portal & $\begin{array}{c}\text { Web } \\
\text { Services }\end{array}$ & 1 & CEO & 4 & High \\
\hline 5 & Small & $\begin{array}{l}\text { Business } \\
\text { Incubator }\end{array}$ & ERP & 2 & $\begin{array}{c}\text { IT Mgr } \\
\text { /Shared } \\
\text { Services } \\
\text { Mgr }\end{array}$ & $4 / 5$ & $\begin{array}{c}\text { High/Medi } \\
\text { um }\end{array}$ \\
\hline 6 & Medium & $\begin{array}{c}\text { Software } \\
\text { Development }\end{array}$ & ERP & 2 & $\begin{array}{l}\text { Project } \\
\text { Mgr/ } \\
\text { Product } \\
\text { Mgr }\end{array}$ & $5 / 4$ & High/High \\
\hline 7 & Medium & $\begin{array}{l}\text { Electric } \\
\text { Company }\end{array}$ & CRM & 1 & IT Mgr & 7 & High \\
\hline 8 & Small & $\begin{array}{c}\text { Software } \\
\text { Development }\end{array}$ & $\begin{array}{c}\mathrm{ERP} / \mathrm{CR} \\
\mathrm{M}\end{array}$ & 1 & $\begin{array}{c}\text { Co- } \\
\text { Founder }\end{array}$ & 6 & High \\
\hline 9 & Medium & $\begin{array}{c}\text { Retail \& } \\
\text { Distribution }\end{array}$ & CRM & 1 & $\begin{array}{c}\text { App } \\
\text { Team } \\
\text { Mgr }\end{array}$ & 5 & Medium \\
\hline 10 & Medium & $\begin{array}{c}\text { Retail \& } \\
\text { Distribution }\end{array}$ & CRM & 3 & $\begin{array}{c}\text { Strategy } \\
\& \\
\text { Busines } \\
\text { s } \\
\text { Develop } \\
\text { ment/ } \\
\text { GM } \\
\text { / PMO }\end{array}$ & $3 / 4 / 6$ & $\begin{array}{l}\text { Medium / } \\
\text { Medium } \\
\text { /High }\end{array}$ \\
\hline 11 & Medium & $\begin{array}{l}\text { Agriculture } \\
\text { Services }\end{array}$ & $\begin{array}{l}\text { Tracking } \\
\text { System }\end{array}$ & 2 & IT Staff & $2 / 4$ & Low/Low \\
\hline
\end{tabular}

Table 1. Sampling Profile 


\section{Organisational Transformation}

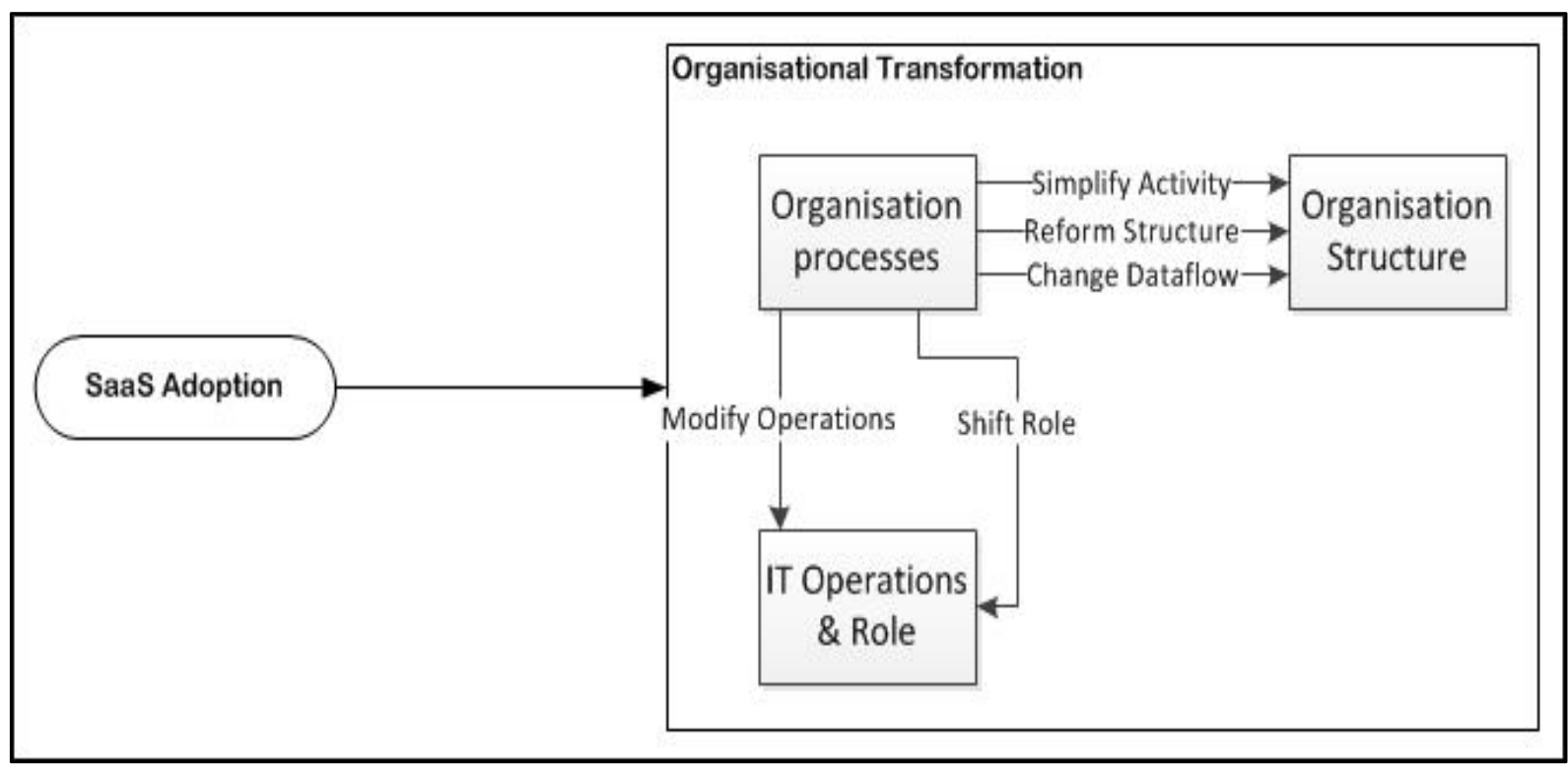

Figure 1 Organisational Transformation Model

Organisational transformation represents potential business transformations that may happen within the organisation after they have adopted SaaS. After a period of time of usage, they realise that due to new functionalities now available to them, they are able to transform their business structures and processes. The degree of the transformation is dependent on the level of diffusion of the system among the organisation's personnel and departments. So, the more the organisation embraces cloud solutions, the more they need to change their business processes, structure and roles. Figure 1. shows a model of the transformations found in this study.

\subsection{Organisation Processes}

These are the changes or transformations that occurred to the organisation's processes as a consequence of SaaS usage. Introducing SaaS based solution within the organisations helps to enhance and improve their processes. SaaS services offer a wide range of solutions targeting organisation such as ERP, CRM and other collaborative solutions. Implementing these solutions can change and improve the entire business process. These changes can be introducing completely new processes or could also be replacing an old process with an improved one.

It is not always the case that the organisations experience a radical or obvious change in their processes. Sometimes, the change simply occurs to the underlying work activities when then change the process itself. For example, the new SaaS solution might reduce the steps needed to accomplish a certain task and change the overarching business process. Change might also be in the form of switching from paperbased processes to electronic forms. Participants reported huge and desired changes in their organisations processes after adopting SaaS services.

"Previously, some tasks had to go through multiple systems to be accomplished which cost us time and effort. Now, we are able to handle them quickly with ease. For example, in the old process if we received 5-6 new users we had to prepare their account and set up the environment then we had to check everything was correctly set up to make instances on our directory. This process was time and effort consuming. It took about $70 \%$ of the process just to setup an account. Now, this $70 \%$ is gone and everything now is a wizard through the application. The remaining $30 \%$ is to support the incubatees and to monitor the systems. We are now focusing on our main mission which is serving the incubatees and to control and develop our environment and network". 


\subsection{Organisation Structure}

These are changes or transformations that occurred to the firms' organisational structure or management structure. Changes in organisational structure involve physical changes to how the firm is organised. These changes may involve adding or terminating departments or units. These changes may occur due to the shifting of duties from one department or unit to another or simply because of the change in the processes which were discusses earlier.

On the other hand, the changes in the firms' management structure can more be regarded as soft changes. These changes are about the reformation of the responsibilities and the workflow within the firm i.e. who reports to whom and who is responsible for whom.

SaaS solutions help to enhance firms' overall efficiency by optimising the firms' processes. Also, it can contribute to the firms' efficiency by helping them to change their organisational structure based on best practise in the industry. This will help the firms to assist the departments properly, so they can decide whether to initiate or terminate departments or to merge them. Similarly, it helps the firms to distribute the work and duties efficiently among the departments and apply policies and boundaries and define responsibilities more clearly.

According to the interviewees, implementing SaaS solutions within the organisation, along with provider's technical and consulting support, helped to change their firms' organisational structure.

"It helps us to be a flatter organisation. For example, we used to have a product manager and a sales rep and they were reporting to what we call the segment manager who also had an area manager to report to, and then we had a division manager. Now, we have only the division, segment and product managers. We used to have 21 division managers in the organisation, now we have only 3 of them".

As mentioned previously, these changes can lead to changes in the firms' management structure e.g. expand, reduce or shift on department's duties to other department/departments or simply to cancel the entire department.

"We no longer need some departments such as Maintenance and Installation; we cancel these teams and shift some of their employees to other departments as needed"

\subsection{IT Department Role}

These are changes or transformations that occurred to the organisation's IT department roles and responsibilities as a result of SaaS usage. From the IT department participants' point of view, cloud is a disruptive technology that is not just disruptive in a technology sense but is also a game changer that disrupts the IT department's job requirements, responsibilities and roles.

The IT department's main goal is to support the business processes. Therefore, any change or changes that happen to the IT department's role and responsibility will certainly affect the way the IT operates. Consequently, the IT department is going to operate differently when adopting SaaS services. Changes in IT operations are not directly because of SaaS adoption itself but rather because of the changes to organisation processes. The change in the process affect the IT role and responsibilities which in turn affect how IT operate based on the new role.

"Now we said to our IT staff: you are going to be more flexible, more valuable and your responsibilities and roles will become to supervise and envision the quality of services and how to deliver the services effectively".

"So, we are existing here as an IT team mainly to rollout new processes, enhance the existing processes, implement the new features that come from the cloud and giving new ideas to SAP to build their strategy and vision".

\section{Relationships}

Relationships between the categories of transformation were also observed in the analysis. These were primarily the different ways changes in organisation processes impact changes in organisation structures and also how changes in organisation processes influence changes in the role of IT department. 


\subsection{Organisation Processes Influence Organisation Structure}

SaaS services offer a wide range of solutions such as ERP, CRM and other collaborative solutions. Introducing SaaS solutions in the organisation brings changes or transformations to an organisation's processes. These changes can be introducing completely new processes or improving the current ones.

Thus, changes in the organisation's processes influence changes in the organisation's departments and management structure. These changes can be actual changes i.e. adding or terminating departments or sections. Also, they can be a reformation of the organisation's departments i.e. responsibilities and/or employees shift from department to another.

The changes in reporting hierarchy and dataflow can also considered as changes in the organisation's managerial structure, which are influenced by changes in the organisation's processes. Hence, the influence of the organisation's processes on the organisation's structure can be seen as the following:

\subsubsection{Simplify Employee Activities}

Usage of SaaS solutions can change the way in which employees perform their activities. These changes can affect the way the employees perform certain task or sets of tasks. Implementing SaaS solution can help simplify and/or reduce steps of the tasks.

The change in employees' activities encourages the organisation to adjust its departments and units to adapt to the change brought by the solution so the work becomes more efficient.

"I think it just removes some steps. It makes it more efficient, the process, removes the need for additional resource and handover. It should reduce the error rate because there's no converting of, in this case, orders from manual version into an electronic version. There's only one step. But it doesn't change the process itself, fundamentally"

"We no longer need some departments such as Maintenance and Installation; we cancel these teams and shift some of their employees to other departments as needed"

\subsubsection{Reform Organisational Structure}

Change in the organisation's processes helps the organisation to automate more processes and adjust other processes. Adding, removing or altering processes requires changes in the organisational structure to maximise the benefits from the reformation.

These changes can lead the organisation to restructure the organisational units. Thus, changes in the organisation's processes influence changes in the firm's organisational structure.

"Back office administration used to have a team to collect data on "data entry, balance, auditing" and we had to double check the errors because we didn't trust this department 10o\%. Now this department is shut down. Why? Because everything is live now and anyone from the head office can generate the needed reports."

\subsubsection{Changes in the Organisation Data Flow}

Some changes in the organisation's processes do not necessarily lead the organisation to restructure its organisational units. However, they can affect the way the organisation deals with data flow and how data flows within and between organisational units. This involves changes in departments' duties and shifting responsibilities from one unit to another.

"It's real time. So, also, the structuring of the Projects Department itself has streamlined a lot. What I mean by that is: previously before this application, people were scattered-so management doesn't know until it was reported specifically what prospective leads that we are waiting for, what's available in the market, what kind of projects we are waiting for. So now, all these kinds of information are flowing directly to management. So it's a big leap for us".

\subsection{Organisation Processes Change IT Department Role}

Changes in organisation processes impact the IT role and operation. The IT department is structured to support the entire organisation's processes. However, when the organisation decided to change its processes to align with the new solution the IT department also needs to change in response. So, the change in the organisation's processes lead to a restructure of the role of the IT department and its operations. 


\subsubsection{Shift in IT Role and Responsibilities}

Change in organisation's processes effect the IT department's role and responsibilities. As the IT role and responsibilities are set based on the needs of the organisation, these need to change when the organisation's needs have changed. IT role and responsibilities shift from being technical to be more strategic, from technical support to a business enabler. After adopting SaaS solutions, the IT department has fewer responsibilities and control over the solution. Therefore, the role changes from maintaining and developing the system to dedicating more time to support the organisation operations.

"Today all our time is dedicated to the clients. The systems maintain themselves so we don't need to monitor the system for degradation, slowness, disconnect, failure"

"The IT department must act as a business enabler and stay away from complicated technical things"

"IT has less responsibility after they go live. Before they go live, for sure IT is there and IT is must. We are the implementer; we are the guys who do the implementation. But after they go live, you feel that there is less responsibility."

\subsubsection{Modify IT Operations}

The IT department operates based on its role and responsibilities. When these roles and responsibilities have changed, the IT operations must change to suit. This will make the IT department operate differently by adding or eliminating some operations. For instance, maintaining the infrastructure, batch management and security threats operations are no longer needed. Instead, the IT department needs cooperate with SaaS provider and report problems.

"So, we exist here as an IT team mainly to roll out new processes, enhance the existing process, implement the new features coming from the cloud and giving new ideas to SAP to build their upgrade and build their strategy vision"

"So Cloud will help us not to worry about backups, not to worry about disasters, not to worry about people who will be there, who will manage the systems; not to worry about the current structure-the current infrastructure we have. So mostly, Cloud will help us to-to, avail services only-and pay only for those services"

\section{Conclusion}

This paper sought to understand how longer term SaaS usage can transform organisations, particularly SMEs. Previous studies into cloud computing adoption have focused on financial and strategic consequences, with relatively few studies exploring organisational transformation in depth. This paper has used a qualitative case study method by using semi-structured interviews. Then, analysing those interviews using a Grounded Theory methodology, developed a model of SaaS usage Organisational Transformation. The types of organisational transformation observed included changes to organisational processes, changes to the structures within the organisations and also changes to the role played by IT departments. Relationships between these forms of transformation were also found.

A greater understanding of these transformations can help organisations, and especially SMEs, to gain greater benefits from the adoption and usage of Software-as-a-Service solutions. Organisations could increase the success of their SaaS solutions by purposely aiming to achieve enhancements and improvements in their business operations as well as the technical benefits that are usually expected. By understanding the potential changes that may occur to their processes, structures and IT operations, organisations can pro-actively plan for and deal with these changes in their implementation plans. The provided conceptual model could benefit both organisations that wish to adopt or have already adopted SaaS solutions and also cloud services providers to assist the adoption process of their clients.

\section{References}

Ahokangas, P., Juntunen, M., and Myllykoski, J. 2014. "Cloud Computing and Transformation of International E-Business Models," in <Italic $>$ a Focused Issue on</Italic $>$ Building New Competences in Dynamic Environments. pp. 3-28.

Al-lawati, A., and Al-Badi, A. H. 2016. "The Impact of Cloud Computing It Departments: A Case Study of Oman's Financial Institutions," 2016 3rd MEC International Conference on Big Data and Smart City (ICBDSC), pp. 1-10. 
Arya, P. K., Venkatesakumar, V., and Palaniswami, S. 2010. "Configurability in Saas for an Electronic Contract Management Application," Proceedings of the 12th international conference on Networking, VLSI and signal processing: World Scientific and Engineering Academy and Society (WSEAS), pp. 210-216.

Avram, M. G. 2014. "Advantages and Challenges of Adopting Cloud Computing from an Enterprise Perspective," Procedia Technology (12), pp. 529-534.

Azarnik, A., Shayan, J., Alizadeh, M., and Karamizadeh, S. 2013. "Associated Risks of Cloud Computing for Smes," Open International Journal of Informatics (1:1).

Beheshti, H. M., and Beheshti, C. M. 2010. "Improving Productivity and Firm Performance with Enterprise Resource Planning," Enterprise Information Systems (4:4), pp. 445472 .

Berman, S. J., Kesterson-Townes, L., Marshall, A., and Srivathsa, R. 2012. "How Cloud Computing Enables Process and Business Model Innovation," Strategy \& Leadership (40:4), pp. 27-35.

Bose, R., and Sugumaran, V. 2008. "Challenges for Deploying Web Services-Based E-Business Systems in Smes," International Journal of E-Business Research (2:1).

Concha, D., Espadas, J., Romero, D., and Molina, A. 2010. "The E-Hub Evolution: From a Custom Software Architecture to a Software-as-a-Service Implementation," Computers in Industry (61:2), pp. 145-151.

Culley, G., and Panteli, N. 2015. "Exploring the Impact of Cloud Computing on It Departments," ECIME2015-9th European Conference on IS Management and Evaluation: ECIME 2015: Academic Conferences and publishing limited, p. 54.

Dubey, A., and Wagle, D. 2007. "Delivering Software as a Service," The McKinsey Quarterly (6:2007), p. 2007.

Eisenhardt, K. M. 1989. "Building Theories from Case Study Research," Academy of management review (14:4), pp. 532-550.

Erdogmus, H. 2009. "Cloud Computing: Does Nirvana Hide Behind the Nebula?," Software, IEEE (26:2), pp. 4-6.

Fisher, T. 2014. "The Cio as Chief Innovation Officer: How Cloud Is Changing the Cio Role." Retrieved 06/06/2018, from https://www.oracle.com/assets/thecioaschiefinnovation-2192468.pdf

Gartner. 2017. "Gartner Says Worldwide Public Cloud Services Market to Grow 18 Percent in $2017, ")$.

Gupta, A. 2000. "Enterprise Resource Planning: The Emerging Organizational Value Systems," Industrial Management \& Data Systems (100:3), pp. 114-118.

Hendricks, K. B., Singhal, V. R., and Stratman, J. K. 2007. "The Impact of Enterprise Systems on Corporate Performance: A Study of Erp, Scm, and Crm System Implementations," Journal of operations management (25:1), pp. 65-82.

Hudli, A. V., Shivaradhya, B., and Hudli, R. V. 2009. "Level-4 Saas Applications for Healthcare Industry," in: Proceedings of the 2nd Bangalore Annual Compute Conference. Bangalore, India: ACM, pp. 1-4.

Hugos, M. H., and Hulitzky, D. 2010. Business in the Cloud: What Every Business Needs to Know About Cloud Computing. John Wiley \& Sons.

Kern, T., Kreijger, J., and Willcocks, L. 2002. "Exploring Asp as Sourcing Strategy: Theoretical Perspectives, Propositions for Practice," The Journal of Strategic Information Systems (11:2), pp. 153-177.

Khajeh-Hosseini, A., Greenwood, D., and Sommerville, I. 2010. "Cloud Migration: A Case Study of Migrating an Enterprise It System to Iaas," 2010 IEEE 3rd International Conference on cloud computing: IEEE, pp. 450-457.

Lacity, M. C., and Reynolds, P. 2014. "Cloud Services Practices for Small and Medium-Sized Enterprises," MIS Quarterly Executive (13:1).

Lewandowski, J., Salako, A. O., and Garcia-Perez, A. 2013. "Saas Enterprise Resource Planning Systems: Challenges of Their Adoption in Smes," e-Business Engineering (ICEBE), 2013 IEEE 1oth International Conference on: IEEE, pp. 56-61. 
Lin, A., and Chen, N.-C. 2012. "Cloud Computing as an Innovation: Percepetion, Attitude, and Adoption," International Journal of Information Management (32:6), pp. 533-540.

Liu, F., Tong, J., Mao, J., Bohn, R., Messina, J., Badger, L., and Leaf, D. 2011. "Nist Cloud Computing Reference Architecture," NIST special publication (500), p. 292.

Low, C., Chen, Y., and Wu, M. 2011. "Understanding the Determinants of Cloud Computing Adoption," Industrial Management \& Data Systems (111:7), pp. 1006-1023.

Mabert, V. A., Soni, A., and Venkataramanan, M. A. 2003. "The Impact of Organization Size on Enterprise Resource Planning (Erp) Implementations in the Us Manufacturing Sector," Omega (31:3), pp. 235-246.

Madapusi, A., and D'Souza, D. 2012. "The Influence of Erp System Implementation on the Operational Performance of an Organization," International Journal of Information Management (32:1), pp. 24-34.

Malladi, S., and Krishnan, M. S. 2012. "Cloud Computing Adoption and Its Implications for Cio Strategic Focus-an Empirical Analysis,").

McKendrick, J. 2011. "Cloud Computing: Ticket to the Corner Office?", 14 May 2018, from https://www.forbes.com/sites/joemckendrick/2011/10/19/cloud-computing-ticketto-the-corner-office/

Oredo, J. O., and Njihia, J. 2014. "Challenges of Cloud Computing in Business: Towards New Organizational Competencies," International Journal of Business and Social Science $(5: 3)$.

Rajendran, S. 2013. "Organizational Challenges in Cloud Adoption and Enablers of Cloud Transition Program." Massachusetts Institute of Technology.

Reuther, D., and Chattopadhyay, G. 2004. "Critical Factors for Enterprise Resources Planning System Selection and Implementation Projects within Small to Medium Enterprises," Engineering Management Conference, 2004. Proceedings. 2004 IEEE International: IEEE, pp. 851-855.

Saul, B., Lynn, K. T., Anthony, M., and Rohini, S. 2012. "How Cloud Computing Enables Process and Business Model Innovation," Strategy \& Leadership (40:4), pp. 27-35.

Shaio Yan, H., Shi-Ming, H., Tung-Hsien, W., and Wen-kai, L. 2009. "Process Efficiency of the Enterprise Resource Planning Adoptionnull," Industrial Management \& Data Systems (109:8), pp. 1085-1100.

Srinivasan, S. 2013. "Is Security Realistic in Cloud Computing?," Journal of International Technology and Information Management (22:4), p. 3.

Strauss, A., and Corbin, J. 1998. Basics of Qualitative Research: Techniques and Procedures for Developing Grounded Theory. Sage publications.

Stuart, M., Udechukwu, O., and Al, S. 2010. "Erp Implementation in Omantel: A Case Study," Industrial Management \& Data Systems (110:1), pp. 78-92.

Taylor, S., Young, A., and Macaulay, J. 2010. "Small Businesses Ride the Cloud: Smb Cloud Watch-Us Survey Results," Cisco Internet Business Solutions Group), pp. 1-13.

Van Belle, J.-P. 2012. "Factors Influencing Saas Adoption by Small South African Organisations," 2012 Conference.

Vijeikis, J., and Makstutis, A. 2009. "Small and Medium-Sized Business Competitiveness in Lithuania," Ekonomika ir vadyba: aktualijos ir perspektyvos (2:15), pp. 328-338.

Yanosky, R. 2008. "From Users to Choosers: The Cloud and the Changing Shape of Enterprise Authority," The tower and the cloud), p. 126.

Zhao, F., Scheruhn, H.-J., and von Rosing, M. 2014. "The Impact of Culture Differences on Cloud Computing Adoption," in Human-Computer Interaction. Applications and Services:, M. Kurosu (ed.). Springer International Publishing, pp. 776-785.

Copyright: (C) 2018 Alshammari, Adamopoulos and Dick . This is an open-access article distributed under the terms of the Creative Commons Attribution-NonCommercial 3.0 Australia License, which permits non-commercial use, distribution, and reproduction in any medium, provided the original author and ACIS are credited. 